\title{
Prognostic value of left ventricular longitudinal strain in patients with aortic stenosis
}

\section{(D)Ante Matana, DTeodora Zaninović Jurjević*, \\ (iD) Slavica Kovačić}

University of Rijeka, Faculty of Medicine, University Hospital Centre Rijeka, Rijeka, Croatia

\author{
KEYWORDS: aortic stenosis, myocardial fibrosis, echocardiography, global longitudinal strain \\ CITATION: Cardiol Croat. 2019;14(3-4):104. | https://doi.org/10.15836/ccar2019.104
}

*ADDRESS FOR CORRESPONDENCE: Teodora Zaninović Jurjević, Klinički bolnički centar Rijeka, Krešimirova 42 , HR-51000 Rijeka, Croatia. / Phone: +385-51-407-149 / Fax: +385-51-218-059 / E-mail: teazj@net.hr

ORCID: Ante Matana, https://orcid.org/0000-0003-3630-0374 • Teodora Zaninović Jurjević, https://orcid.org/0000-0001-8359-3910 Slavica Kovačić, https://orcid.org/0000-0002-7419-224X

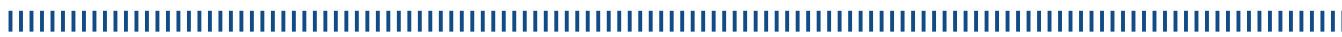

Left ventricular (LV) hypertrophy in patients with aortic stenosis (AS) is an adaptive mechanism that tries to maintain left ventricular systolic function despite obstruction. ${ }^{1}$ The appearance of myocardial fibrosis (MF) is a turning point from adaptive hypertrophy to maladaptation, that changes ventricular function and represents the basis for development of ventricular arrhythmias. There are two types of MF: reversible interstitial MF in early stage, and irreversible replacement MF in the later stage of disease. MF occupies LV midwall, usually in LV posterobasal part.

Cardiac magnetic resonance (CMR) by late gadolinium enhancement (LGE) is the "gold standard" in diagnosis of replacement MF. Positive LGE results indicate significantly greater risk of adverse outcome than it is in patients without MF. Echocardiography suggests the presence of MF with significant reliability, because global longitudinal strain (GLS) shows good correlation with results of CMR. Consequently, GLS can serve as a surrogate marker of MF and an indicator of adverse events in AS. . $^{2-4}$ MF mostly influences LV longitudinal function, while circumferential and radial deformation are less modified. In severe compensated AS circumferential deformation and apical rotation (ApR) are increased, what is likely a compensative mechanism for keeping cardiac output. The increased ApR is also associated with worse survival. With disease progression these compensative changes disappear. Mechanical dispersion (MD) is an indicator of contractile heterogeneity caused by fibrosis. Increased MD demonstrates significant association with mortality and can serve as an additional prognostic parameter. Along with more extensive MF the risk for sudden cardiac death increases what raises the question of the benefit of cardioverter-defibrillator

In conclusion, impaired GLS suggests MF, what must be confirmed by CMR. MF classifies the patients with severe asymptomatic AS into the group with increased risk of adverse outcome. Therefore, it is to be expected that these new facts will result in new guidelines for treatment of severe asymptomatic AS.
RECEIVED:

February 28, 2019

ACCEPTED:

March 24, 2019

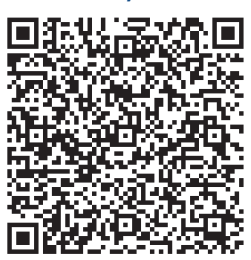

$\square$ Cardiologia Croatica 2019;14(3-4):104.
10. hrvatski dvogodišnji ehokardiografski kongres s međunarodnim sudjelovanjem $10^{\text {th }}$ Croatian Biennial Echocardiography Congress with International Participation Poreč, 16. do 18.5.2019.

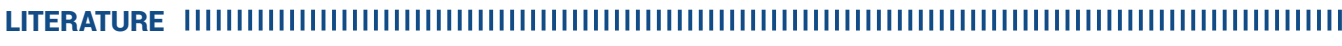

1. Mistiaen WP. The changes in left ventricular structure-function relationship in aortic valve stenosis. OA Anatomy. 2014 Sep 17;2(3):24. Available from: http://www.oapublishinglondon.com/article/1540 (February 20, 2019).

2. Kusunose K, Goodman A, Parikh R, Barr T, Agarwal S, Popovic ZB, et al. Incremental prognostic value of left ventricular global longitudinal strain in patients with aortic stenosis and preserved ejection fraction. Circ Cardiovasc Imaging 2014;7:938-45. https://doi.org/10.1161/CIRCIMAGING.114.002041

3. Fries B, Liu D, Gaudron P, Hu K, Nordbeck P, ErtI G, et al. Role of Global Longitudinal Strain in the Prediction of Outcome in Patients With Severe Aortic Valve Stenosis. Am J Cardiol. 2017 Aug 15:120(4):640-647. https://doi.org/10.1016/j.amjcard.2017.05.032

4. Klaeboe LG, Haland TF, Leren IS, Ter Bekke RMA, Brekke PH, Røsjø H, et al. Prognostic Value of Left Ventricular Deformation Parameters in Patients with Severe Aortic Stenosis: A Pilot Study of the Usefulness of Strain Echocardiography. J Am Soc Echocardiogr. 2017 Auq;30(8):727-735.e1. https://doi.org/10.1016/j.echo.2017.04.009 